\title{
Risk Factors and Epidemiology of Gastric Cancer in Pakistan
}

\author{
Muhammad Daniyal', Saeed Ahmad'2, Mukhtiar Ahmad ${ }^{3}$, Hafiz Muhammad \\ Asif $^{4}$, Muhammad Akram ${ }^{4}$, Saif Ur Rehman ${ }^{4}$, Sabira Sultana ${ }^{3}$
}

\begin{abstract}
Gastric cancer is the 2nd most common cause of death among all cancers and is the 4th most common cancer in the world. The number of deaths due to gastric cancer is about 800,000 annually. Gastric cancer is more common in men as compared to women and is 3rd most common cancer after colorectal and breast cancers in women. A progressive rise in the incidence rate has been observed in females over the last 5 years. The highest incidence of stomach cancer is in China, South America and Eastern Europe. The incidence of gastric cancer has 20 fold variation worldwide. Global variation is linked by two factors which play important role in developing gastric cancer. One is infection with Helicobacter pylori and the $2^{\text {nd }}$ is diet. South Asia is a region with low risk, despite a high prevalence of $\boldsymbol{H}$.pylori. Gastric carcinoma is common in southern region of India. Gastric cancer is more readily treated if diagnosed early. This study aims to provide awareness about gastric cancer as well as an updated knowledge about risk factors and epidemiology of gastric cancer in Pakistan.
\end{abstract}

Keywords: Epidemiology - risk factors - gastric cancer - Pakistan - literature review

Asian Pac J Cancer Prev, 16 (12), 4821-4824

\section{Introduction}

Carcinoma of the stomach is $2^{\text {nd }}$ most common cancer in the world. According to a worldwide estimation the mortality ratio of stomach cancer is 19.1 and stomach cancer is most common cancer in men after lung cancer. Gastric cancer is usually seen more in low socio economic group. Increase incidence of the lesion at the cardiac end of the stomach has been associated with adenocarcinoma of the lower esophagus and obesity is common risk factors (Roder et al., 2002). According to Scandinavian study weight loss, epigastric pain $(63.3 \%)$ and gastrointestinal hemorrhage $(27.3 \%)$ were the important symptoms (Iqbal et al., 2005). The gastric carcinoma in distal part of the stomach is more common but can occur in any part of the stomach. Nearly $37 \%$ of the gastric carcinoma in US originates from upper third of the stomach and $20 \%$ originate from middle third and $30 \%$ in the lower third and $12 \%$ involves the entire stomach, but the distal tumors have 5 years survival rate of nearly 20 to $25 \%$ after surgery (Durrani et al., 2009). Chong et el stated that prevalence of gastric cancer is decreasing but morbidity and mortality due to gastric cancer is still significant (Chong et al., 2014). In Europe and United States, many patients with gastric cancer are diagnosed at later stages when metastasis occurs. Sign and symptoms are usually weight loss, anorexia and epigastric pain. In initial stage of gastric cancer, $\mathrm{H} 2$ receptor antagonists or antacids reduce symptoms but are less effective in advance stage of disease. Large cancer of prepyloric region or antrum may cause gastric outlet obstruction. Anemia occurs due to chronic bleeding and presence of occult blood in the stools. Dysphagia is observed in patients with cancer of esophagogastric junction.

\section{Risk factors}

No single factor is involved in stomach cancer. $H$. pylori has strong association with various gastric pathologies such as gastric adenocarcinoma, gastric MALT lymphoma, peptic ulcer and type B antral enteritis (Jing et al., 2012; Karami et al., 2013). Ahmed et al reported that $H$. pylori is risk factor of gastric cancer in Pakistan. Most common cause of gastric cancer is H. pylori infection in Pakistan. Gastric cancer is most common in patients with H.pylori infection in Pakistan. Prevalence of gastric cancer is three times more in Patients with seropositive for $H$. pylori than seronegative $H$. pylori in Pakistan (Ahmad et al., 2009). Ejaz et al conducted a study in rural areas of Pakistan and reported that use of pesticides is common cause of cancer in rural areas of Pakistan (Ejaz et al., 2004).Zeb et al reported that probable

${ }^{1}$ Faculty of Eastern Medicine and Surgery, Hamdard University, Karachi, ${ }^{2}$ Department of Pharmacy, Faculty of Pharmacy \& Alternative Medicine, The Islamia University of Bahawalpur, ${ }^{3}$ University College of Conventional Medicine, Faculty of Pharmacy \& Alternative Medicine, The Islamia University of Bahawalpur, faculty of Medical and Health Sciences, The University of Poonch, Rawalakot, Azad Jammu \& Kashmir, ${ }^{4}$ Faculty of Medical and Health Sciences, The University of Poonch, Rawalakot, Azad Jammu \& Kashmir, Pakistan*For correspondence: daniyaldani151@yahoo.com 
and the most important reason for high incidence of cancer in distract Dir, Pakistan is little rest, high burden of work, low intake of antioxidant and illiteracy (Zeb et al., 2006). Khan et al reported that $H$. pylori is highly prevalence in Pakistan, that is most common risk factor for development of gastric cancer (Khan et al., 2013). Bhurgri et al., stated that less use of vegetables and cigarette smoking are major risk factors of gastric cancer in Pakistan (Bhurgri et al., 2004). Risk factor for $H$. pylori infection includes unsafe water supply, consumption of raw foods, overpopulation and poor sanitary conditions (Zhong et al., 2012). Risk factor for development of gastric cancer is occurs due to cigarette smoking. Incidence of gastric cancer increases with duration of the habits and amount of cigarette smoked. Gastric cancer is more common in people eating large amount of pickled vegetables, meat, smoked fish and starch. Study show that nitrosamines are involved in development of cancer in animals and may play role in development of gastric cancer in humans. Dietary nitrates and nitrites are converted to nitrosamine by the action of $H$. pylori and other bacteria. Fresh vegetables, whole milk and vitamin $\mathrm{C}$ and other antioxidant prevent the development of gastric cancer. Prevalence of gastric cancer is more in people with hereditary nonpolyposis colorectal cancer (HNPCC) syndrome. Germline mutation in the gene for E-cadherin (CDH1) is responsible for incidence of diffuse gastric cancer. In one study data showed the that expression of autocrine motility factor receptor (AMFR) was a risk factor representing poor prognosis in patients with stomach cancer following surgical resection (Li et al., 2013). Gastric adenomatous polyps, subtotal gastrectomy, pernicious anemia, autoimmune gastritis and atrophic gastritis are associated with development of gastric cancer. In one study, prevalence of helicobacter pylori infection in patients who usually consumed unboiled water was $61.6 \%$ which was higher than those who drink boiled water $(30.8 \%)$. The water quality has strong effects on prevalence of $\mathrm{H}$ pylori infection (Mitipat et al., 2005). Campos et al reported that Epstein-Barr is virus associated with gastric cancer in Colombia (Campos et al., 2006). Studies indicate that EBV causes molecular changes that lead to gastric cancer. Characteristics of EBV associated gastric cancer differentiate from characteristics of Helicobacter pylori associated gastric cancer (Malakar et al., 2014; Tuncel et al., 2014).

\section{Worldwide prevalence}

Gastric cancers remain main cause of death among people of United States up to mid- 20th century, now it is $3 \%$ of cancer deaths among people of the United States. Prevalence of gastric cancer is 7 to 8 times more in Chile and Japan than United States. Highest prevalence of gastric cancer is observed in Japan. Incident rates are highest in Japan (in men 77.9 per 100000 and in women 33.3) (Maxwell et al., 1999). Prevalence of gastric cancer is ten times as frequent as observed in American whites. High prevalence is also seen in Latin America. Gastric cancer is also common in Eastern Europe and Iceland. Mortality rate due to cancer in Japan was $6.8 / 100,000$ (Aoki, 2006). In Korea, number of death due to cancer was 72,046 in 2010 that is $28 \%$ of all death.

High prevalence of gastric cancer was reported in different regions of Iran (Sadjadi et al., 2003). Incidence of gastric cancer is 19.7 per 100000 people in Semnan province in Iran (Babaei et al., 2005). In a study conducted in Guilan province confirmed that chronic gastritis, atrophy and dysplasia are more common in stomach cancer relatives as compared to control group (Mansour-Ghanaei et al., 2012). Cancer related deaths are more common in gastric cancer and is the fourth most commonly diagnosed cancer in the World. More than one million people are diagnosed with stomach cancer annually (Basiri et al., 2014; Deng et al., 2014; Khoshbaten et al., 2014; Karim et al., 2014; Unal et al., 2014; Yang et al., 2014; Zhou et al., 2014).In South Australia, its mortality has been reduced nearly $40 \%$ since last 20 years due to better refrigeration. Mohammad et al reported prevalence of gastric cancer in Brunei Darussalam and stated that it is $2^{\text {nd }}$ most common among gastrointestinal cancers (Mohammad et al., 2014). Prevalence of gastric cancer is high in China (Lu et al., 2014). Prevalence of gastric cancer in male to female ratio was 1.2:1 (Abdifard et al., 2013). Prevalence of gastric cancer is more in Iran as compared to western countries (Sadjadi et al., 2003). Prevalence of gastric cancer is decreasing due to decline in prevalence of helicobacter pylori infection and improvement in living standard (Atrkar et al., 2013). In Iranian population, new cases of cancer are 50,000 in the 75 million populations annually and GIT tracks cancer are $38 \%$ of all cancer cases (Pourhoseingholi, 2008). Prevalence of esophageal cancer is high in northern Iran (Mohagheghi and Mosavi, 2010). Occurrence of gastric cancer is uncommon in people below 30 years of age and incidence of gastric cancer increases in people above 50 years of age. Gastric cancer is endemic in Japan and age of onset of gastric cancer is lower in Japanese people. Prevalence of gastric cancer is more in male as compared to female. Incidence of gastric cancer is more in American blacks than American whites.

\section{Prevalence in Pakistan}

Carcinoma stomach is commonly present in males (Byrne et al., 2002). In Pakistan one study shows that carcinoma stomach was seen mostly in young male patients, presenting late with advanced disease in stage III and IV in emergency. Only $33 \%$ tumors were resectable while $66.7 \%$ patients were managed by palliative treatment. Overall mortality was $13.3 \%$ due to its late presentation (Shahida et al., 2011). Prevalence of stomach cancer in south and central Asia are identified as low to moderate. Curado stated that incidence in males in different cancer registries in India, on the south east border of Pakistan ranges from 3.4 per 100,000 in Delhi to 12.2 per 100,000 in Trivandarm to 6 per 100,000 in Chennai (Curado et al., 2007). Prevalence of gastric cancer in Karachi was 6 per 100,000 in males and 3.6 per 100,000 in female respectively. Iran, further north Marjani has a reported incidence of 11.2 per 100,000 persons. Marjani reported incidence of gastric cancer in Iran that is 11.2 per 100,000 persons that falls into a higher risk region, in comparison to Karachi (Marjani et 
al., 2007). One study of gastric carcinoma conducted in Peshawar Pakistan shows that $60 \%$ patients belonged to northern part of the province, $30 \%$ were from Southern area, $6 \%$ from the western area whereas $4 \%$ were from eastern side. Adenocarcinoma was the common (100\%) histological type. No gastric lymphoma was found (Aman et al., 2003). Bhurgri stated that gastric cancer incidence is increasing in Karachi in males above 40 years of age. The male to female ratio was 2:1 in Karachi (Bhurgri et al., 2009). Mortality rate of gastric cancer in Pakistan is 6541 deaths per year. The incidence of $H$. pylori infection is very high in Pakistan and number of cases is increasing due to unavailability of diagnostic and treatment facilities at public sector. Zubair's study shows that the all Gastric cancer patient of Karachi are diagnosed at very late stage in these patients full thickness of gastric wall is involved with positive lymph node (Zubair et al., 2007).

\section{Conclusion and Future Prospects}

Gastric cancer is a major health issue among Pakistani population. If it is not diagnosed properly and timely, it can become a life-threatening situation. H. pylori is the major risk factor in Pakistan. The incidence and prevalence of gastric carcinomas are increasing worldwide due to decrease intake of fruits and vegetables that contains antioxidants and vitamins which helps us to boost our immune system, and increase intake of noxious and contaminated food such as food from stalls or packed in tinn or jars and harmful substances such as tobacco naswaar, gutkha etc or use of unsterile syringes, physical inactivity etc. Community based health education programs are therefore urgently needed, which give awareness regarding early diagnosis and sign and symptoms of gastric cancer. Mortality rate of gastric cancer is increasing because of the late diagnosis, late seeking for medical help. Emphasis should be given on prevention and timely diagnosis of gastric cancer so that to give the patients better opportunities for gastric cancer treatment. The use of modern diagnostic tools and timely diagnosis will improve mortality and morbidity. Health education of community regarding $H$. pylori and early treatment of gastric cancer will prove useful as preventive measures. So by decreasing and identifying the risk factors and evaluating the patient, it is possible to improve the prognosis so far as the morbidity and mortality of gastric cancer patients. Aggressive screening is suggested and arrangement of awareness programs should be made. Risk factors predisposing to high prevalence of gastric cancer should be identified and dealt with. The measures should have been performed to control this and to change our lifestyle and to decrease the gastric carcinoma in developing countries.

\section{References}

Abdifard E, Ghaderi S, Hosseini S, et al (2013). Incidence trends of colorectal cancer in the West of Iran during 2000-2005. Asian Pac J Cancer Prev, 14, 1807-11.

Ahmad T, Sohail K, Rizwan M, et al (2009). Prevalence of Helicobacter pylori pathogenicity associated cagA and
Risk Factors and Epidemiology of Gastric Cancer in Pakistan

vacA genotypes among Pakistani dyspeptic patients. FEMS Immunol Med Microbiol, 55, 34-8.

Aman U, Ziauddin I, Khalid M (2003). Geographical distribution and histological presentation of gastric carcinoma in NWFP. J Postgrad Med Inst, 17, 111-5.

Aoki K (2006). Early history of cancer epidemiology and prevention in Japan. Asian Pac J Cancer Prev, 7, 170-6.

Atrkar Z, Kazemnejad A, Mansour F, et al (2013). Trend analysis of gastrointestinal cancer incidences in Guilan province: comparing rates over 15 years. Asian Pac J Cancer Prev, 14, 7587-93.

Babaei M, Mousavi S, Malek M, et al (2005). Cancer occurrence in Semnan Province, Iran: results of a population-based cancer registry. Asian Pac J Cancer Prev, 6, 159-64.

Basiri Z, Safaralizadeh R, Bonyadi MJ, et al (2014). Helicobacter pylori vacA d1 genotype predicts risk of gastric adenocarcinoma and peptic ulcers in northwestern Iran. Asian Pac J Cancer Prev, 15, 1575-9.

Bhurgri Y, Faridi N, Kazi LA, et al (2004). Cancer esophagus Karachi 1995-2002: epidemiology, risk factors and trends. $J$ Pak Med Assoc, 54, 345-8.

Bhurgri Y1, Pervez S, Kayani N, et al (2009). Rising incidence of gastric malignancies in Karachi, 1995-2002. Asian Pac J Cancer Prev, 10, 41-4.

Byrne JP, Mathers JM, Parry JM, et al (2002). Site distribution of oesophagogastric cancer. J Clin Pathol, 55, 191-4.

Campos FI, Koriyama C, Akiba S, et al (2006). Environmental factors related to gastric cancer associated with Epstein-Barr virus in Colombia. Asian Pac J Cancer Prev, 7, 633-7.

Chong VH, Telisinghe P, Abdullah MS (2014). Gastric cancer in Brunei Darussalam: epidemiological trend over a 27 year period (1986-2012). Asian Pac J Cancer Prev, 15, 7281-5.

Curado MP, Edwards B, Shin HR, et al (2007). Cancer incidence in five continents. IARC Sci Pub, 9, 160.

Deng W, Long L, Li JL, et al (2014). Mortality of major cancers in Guangxi, China: sex, age and geographical differences from 1971 and 2005. Asian Pac J Cancer Prev, 15, 1567-74.

Durrani A, Yaqoob A, Abbasi N (2009). Pattern of upper gastrointestinal malignancies in northern Punjab. Pak $J$ Med Sci, 25, 302-7.

Ejaz S, Akram W, Lim CW, et al (2004). Endocrine disrupting pesticides: a leading cause of cancer among rural people in Pakistan. Exp Oncol, 26, 98-105.

Iqbal M, Khan M, Tariq B (2005). Gastric Carcinoma: 5 years survival after gastric surgery. J Pak Med Assoc, 55, 158.

Jing C, Huang ZJ, Duan YQ, et al (2012). Glulathionestransferasesgene polymorphism in prediction of gastric cancer risk by smoking and helicobacter pylori infection status. Asian Pac J Cancer Prev, 13, 3325-8

Karami N, Talebkhan Y, Saberi S, et al (2013). Seroreactivity to Helicobacter pylori antigens as a risk indicator of gastric cancer. Asian Pac J Cancer Prev, 14, 1813-7.

Karim S (2014). Clinicopathological and p53 gene alteration comparison between young and older patients with gastric cancer. Asian Pac J Cancer Prev, 15, 1375-9.

Khan A, Farooqui A, Raza Y, et al (2013). Prevalence, diversity and disease association of Helicobacter pylori in dyspeptic patients from Pakistan. J Infect Dev Ctries, 7, 220-8.

Khoshbaten M, Pishahang P, Nouri M, et al (2014). Diagnostic value of fecal calprotectin as a screening biomarker for gastrointestinal malignancies. Asian Pac J Cancer Prev, 15, 1667-70.

Li FX, Zhang RP, Liang H, et al (2013). Validity and necessity of sub-classification of N3 in the 7th UICC TNM stage of gastric cancer. Asian Pac J Cancer Prev, 14, 2091-5.

Lu YF, Liu Z, Li Z, et al (2014). Esophageal/gastric cancer screening in high-risk populations in Henan Province, China. 
Asian Pac J Cancer Prev, 15, 1419-22.

Malakar M, Devi KR, Phukan RK, et al (2014). p53 codon 72 polymorphism interactions with dietary and tobacco related habits and risk of stomach cancer in Mizoram, India. Asian Pac J Cancer Prev, 15, 717-23.

Mansour-Ghanaei F, Joukar F, Baghaei SM, et al (2012). Gastric precancerous lesions in first degree relatives of patients with known gastric cancer: a cross-sectional prospective study in Guilan Province, north of Iran. Asian Pac J Cancer Prev, 13, 1779-82.

Marjani A, Kabir MJ, Semnani S (2007). Stomach cancer incidence among males in Golestan province, Iran. Indian J Gastroenterol, 26, 299.

Maxwell D, Paola P, Ferlay J (1999). Estimates of the worldwide incidence of 25 major cancers in 1990. Int J Cancer, 80, 827-41.

Mitipat N, Siripermpool P, Jadwattanakul T (2005). The prevalence of Helicobacter pylori infection in patients with gastrointestinal symptoms in Chon Buri, Thailand, Southeast. Asian J Trop Med Public Health, 36, 341-6.

Mohagheghi M, Mosavi-Jarrahi A (2010). Review of cancer registration and cancer data in Iran, a historical prospect. Asian Pac J Cancer Prev, 11, 1155-7.

Mohammad IA, Bujang MR, Telisinghe PU, et al (2014). Cancers of the young population in Brunei Darussalam. Asian Pac J Cancer Prev, 15, 6357-62.

Pourhoseingholi A, Pourhoseingholi MA, Vahedi M, et al (2008). Relation between demographic factors and type of gastrointestinal cancer using probit and logit regression. Asian Pac J Cancer Prev, 9, 753-5

Roder M (2002). The epidemiology of gastric cancer. Gastric Cancer, 5, 5-11.

Sadjadi A, Nouraie M, Mohagheghi MA, et al (2005). Cancer occurrence in Iran in 2002, an international perspective. Asian Pac J Cancer Prev, 6, 359-63.

Shahida P, Farhat B, Shafiq R (2011). Pattern and presentation of carcinoma stomach. J Coll Physicians Surg Pak, 21, 161-63.

Tuncel T, Karagoz B, Haholu A, et al (2014). Immunoregulatory function of HLA-G in gastric cancer. Asian Pac J Cancer Prev, 14, 7681-4.

Unal D, Oguz A, Acmaz B, et al (2014). Lack of any association between season of diagnosis and survival of gastric cancer cases in Kayseri, Turkey. Asian Pac J Cancer Prev, 15, 1763-6.

Yang TF, Guo L, Wang Q (2014).Meta-analysis of associations between four polymorphisms in the matrix metalloproteinases gene and gastric cancer risk. Asian Pac J Cancer Prev, 15, 1263-7.

Zeb A, Rasool A, Nasreen S (2006). Occupation and cancer incidence in district Dir (NWFP), Pakistan, 2000-2004. Asian Pac J Cancer Prev, 7, 483-4.

Zhong C, Li NK, Bi JW, et al (2012). Sodium intake, salt taste and gastric cancer risk according to helicobacter pylori infection, smoking, histological type and tumor site in China. Asian Pac J Cancer Prev, 13, 2481-4.

Zhou RP, Chen G, Shen ZL, et al (2014).Cinobufacin suppresses cell proliferation via miR-494 in BGC- 823 gastric cancer cells. Asian Pac J Cancer Prev, 15, 1241-5.

Zubair A, Romana I, Najamul S, et al (2007). Gastric carcinoma: typing, staging, lymph node and resection margin status on gastrectomy specimens. J Coll Physicians Surg Pak, 17, 539-42. 